\title{
Word of Caution: Negative Impact of Mouthwashes on Folded Platelet-Rich Fibrin (F-PRF) Membrane Viability
}

\author{
Lajos Csönge ${ }^{1, *}$, Ágnes Bozsik¹, Zoltán Tóth Bagi², Róbert Gyuris ${ }^{3}$, Dóra Kinga Csönge ${ }^{4}$, and János Kónya ${ }^{5}$ \\ ${ }^{1}$ West Hungarian Regional Tissue Bank, Petz A. University Teaching Hospital, Győr, Hungary \\ ${ }^{2}$ Private praxis, Budapest, Hungary \\ ${ }^{3}$ Private praxis, Eger, Hungary \\ ${ }^{4}$ Pepperdine University, Malibu, CA, USA \\ ${ }^{5}$ Dent-Art-Technik Ltd, Győr and Széchenyi University, Győr, Hungary
}

*Corresponding author: Lajos Csönge, MD, West Hungarian Regional Tissue Bank, Petz A. University Teaching Hospital, Győr, H-9024, Hungary, E-mail: luisbathhelena@gmail.com

Received: 29 Nov, 2021 | Accepted: 09 Dec, 2021 | Published: 16 Dec, 2021

Citation: Csönge L, Bozsik A, Bagi ZT, Gyuris R, Csönge DK, et al. (2021) Word of Caution: Negative Impact of Mouthwashes on Folded Platelet-Rich Fibrin (F-PRF) Membrane Viability. Int J Dent Oral Health 8(1): dx.doi.org/10.16966/2378-7090.385

Copyright: (C) 2021 Csönge L, et al. This is an open-access article distributed under the terms of the Creative Commons Attribution License, which permits unrestricted use, distribution, and reproduction in any medium, provided the original author and source are credited.

\begin{abstract}
Background: The number of clinical applications of different Platelet-Rich Fibrin (PRF) membranes has increased in regenerative medicine including regenerative dentistry. Intact platelets, leukocytes and stem cells of PRF play a crucial role in the local bone augmentation releasing cytokines and growth factors. An integral part of the post-surgical management is the application of mouthwashes, especially chlorhexidine digluconate, which is recommended in order to prevent postoperative infections. In some cases, it is possible that there is contact between the mouthwash and PRF membrane. Therefore, the impact of mouthwashes on cell viability of folded F-PRF was tested.

Method: 3 mouthwash brands were tested: Chorsodyl, Listerine 6 in 1, and Elmex Sensitive Plus using MTT viability assay after 30-second treatment and 72-hour treatment (twice daily for 30 seconds). The membrane samples were incubated in cell culture conditions.

Results: A 30-second mouthwash treatment significantly diminished the fresh F-PRF viability by $15-21 \%$ depending on the agent. After 72 hours of treatment, the viability loss was $\sim 50 \%$.

Conclusion: The decreased number of platelets and other blood cells cannot launch optimal bone morphogenesis. The MTT assay is a cheap, reliable, and simple method to assess the platelet and cellular viability and potential regenerative capacity of F-PRF membrane, or any type of platelet-rich product. The isolation of the PRF membrane from oral liquids and/or application of less aggressive mouthwashes are recommended for at least 5-7 days after PRF surgery.
\end{abstract}

Keywords: Mouthwash; F-PRF; Viability; MTT assay; Regenerative dentistry

Abbreviations: CHX: Chlorhexidine; DMEM: Dulbecco's Minimal Essential Medium; F-PRF: Folded Platelet-Rich Fibrin; Lcs: Leukocytes; MTT Assay: Methyl Tetrazolium Assay; PBS: Phosphate Buffered Saline; PIs: Platelets; Rbcs : Red Blood Cells

\section{Introduction}

Over the last two decades, the number of reports concerning the clinical application of different platelet-rich membranes (PRF) in oral surgery and implant dentistry has increased. There are many articles on the treatment of oroantral fistulas, preparation of sticky bone for augmentation, and post-extraction socket healing as well [16]. The integral part of postoperative management is rinsing using Chlorhexidine-Digluconate (CHX) twice or three times daily for 30 seconds to kill or decrease the number of pathogenic bacteria, in order to prevent postoperative infections $[2,4,6]$. Sometimes, in spite of doctors' recommendations, patients use mouthwash more frequently at home due to postoperative malodor or bad taste in their mouths. Mouthwash can modify a healthy oral microbiome, however, frequent mouthwash use can destroy it $[7,8]$. CHX has a deleterious effect on gingival fibroblast viability, collagen synthesis, and wound healing [9].

Undoubtedly, there is either a short or long-term direct contact between liquids in the oral cavity (saliva, drinks, mouthwashes, etc.) and the implanted PRF membranes through the holes of sutures depending on the speed of epithelialization and closure of wounds. If the PRF membrane cannot be separated perfectly from the oral cavity, there is a chance for contact. Moreover, even some surgical techniques left the wound open and margins are not closed primarily after PRF membrane implantation $[2,5]$.

The main effect of platelet-rich products is based on the theory of regenerative properties of the autologous cells like leukocytes (LCs), 
platelets (PLs), and stem cells. They release cytokines and growth factors for 2-3 weeks in vitro, playing a crucial role in bone and soft tissue regeneration [10].

PRF is a special mixture of individual cells entrapped in a freshly nascent fibrin clot, which later serves as auto scaffold. Fibrin network is permeable for liquids, so these cells are very vulnerable and harmful agents of mouthwashes can injure or destroy cell viability. The decrease of viable cells diminishes cytokine and growth factor release, and thus limits the chance for an optimal local tissue morphogenesis. In spite of many successful reported clinical cases concerning the clinical application of PRF membranes with postoperative mouthwash rinsing, it is the few failed cases that compelled us to investigate the possible reasons as to why. One of those possible reasons is the effect of postoperative mouthwashes.

The chosen MTT viability assay first described by Mosmann is based on the conversion of yellow tetrazolium salt, 3-(4,5-dimethylthiazol2-yl)-2,5-diphenyltetrazolium bromide (MTT) to the purple-colored formazan pigment using mitochondrial enzymes in viable cells [11]. The assay has been widely used in studies on chemosensitivity, cell stimulation in immunology, cytotoxicity, fungal, worm, and cellular studies [12-19].

There have only been a few studies published on solid tissues and none have examined PRF membranes $[16,18,20]$.

Since activity of mitochondrial enzymes involved in the very vulnerable respiratory chain is required for cellular survival, assessment of this enzymatic activity can be used as a surrogate marker of cell viability. Mitochondrial enzyme activity will decline and ultimately cease in lethally damaged cells. As autolysis advances, the activity of mitochondrial enzymes in the respiratory chain (e.g., succinic dehydrogenase and cytochrome oxidase) approaches zero in 24 to 36 hours [21-23]. The formazan pigment produced by mitochondrial enzymes is not water soluble, but after extraction using a suitable organic solvent, its concentration can be measured by a spectrophotometer. The maximal absorbance found was @563 $\mathrm{nm}$ via spectrophotometer (Jenway 6300, UK). After weighing, the samples were incubated in 24 well plates overnight at $37^{\circ} \mathrm{C}$ in $1 \mathrm{ml}$ ethylene glycol monomethyl ether (methyl cellosolve, Sigma) in order to extract the formazan. The resulting color density is proportional to the mitochondrial enzyme activity and, reflective of cell viability, regardless of the cell cycle state.

The main aim of the study is to investigate the impact of mouthwashes on F-PRF viability and adapt MTT viability assay in platelet-rich product studies.

\section{Materials and Methods}

\section{Viability assay after 30-second of treatment}

Twelve tubes of blood were collected from one volunteer donor into a $9 \mathrm{ml}$ Vacuette tubes without anticoagulants (Gerner BioOne, Germany). A folded F-PRF membrane was created from $50 \mathrm{ml}$ plasma as reported earlier [24]. It contained many PLs and LCs as well.

The membrane was cut into 20 uniform pieces and four groups were created (consisting of 5 pieces each). Group \#1 (G1) served as a negative control without any treatment. In group 2 (G2) the pieces were submerged into $0.2 \%$ chlorhexidine - digluconate (Chorsodyl ${ }^{\oplus}$, GSK, UK) for exactly 30 seconds at room temperature. In group 3 (G3), pieces were submerged into Listerine ${ }^{\star} 6$ in 1 (Johnson \& Johnson Consumer Inc., USA) and in group 4 (G4) the pieces were submerged into Elmex ${ }^{\otimes}$ Sensitive Plus (Colgate-Palmolive, Poland) for 30 seconds at room temperature. None of the mouthwashes contained alcohol. After treatment the F-PRF pieces were washed in PBS for 10 seconds to remove the mouthwash.

Subsequently a viability assay was performed to assess the cellular viability of the membrane. A fresh MTT (Sigma, USA) solution was made, while the powder was dissolved in PBS and stored at $4^{\circ} \mathrm{C}$. F-PRF pieces were incubated separately in $500 \mu \mathrm{l} 0.1 \%$ MTT for 1 hour at $37^{\circ} \mathrm{C}$ in 24 well plates. The reaction was halted by transferring the specimens into distilled water for 1 minute.

The absolute viability index was expressed as optical absorbance $@ 563 \mathrm{~nm} / \mathrm{mg}$ F-PRF/ml Cellosolve but in figure 1 it was transformed to relative percent, the fresh 30-second control group (G1) average was set at $100 \%$. Unpaired two-sample t-tests were performed to compare viability index differences of the four groups.

\section{Viability assay after 3 days}

20 other F-PRF membrane pieces from 12 tubes of blood were also assessed after 72 hours of incubation in cell culture conditions in a

\section{IMPACT OF MOUTHWASHES ON F-PRF VIABILITY}

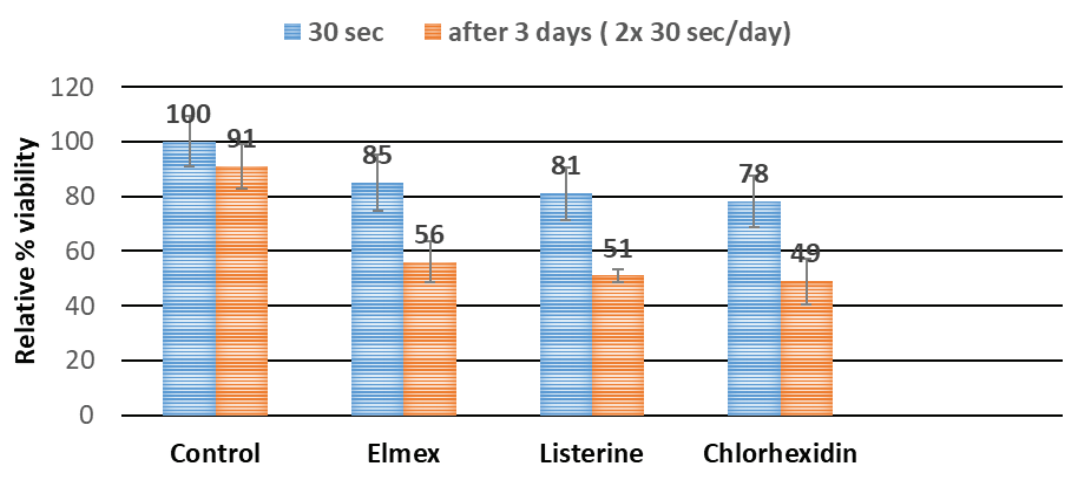

Figure 1: Viability results after mouthwash treatment of F-PRF membranes. 
$\mathrm{CO}_{2}$ incubator (Heracell 150, Germany). The samples were incubated in $1 \mathrm{ml}$ Dulbecco's Minimal Essential Medium (DMEM) with $0.1 \%$ trypsin (Sigma, USA) and $0.4 \mathrm{mg} / \mathrm{ml} \mathrm{EDTA} \mathrm{at} 37^{\circ} \mathrm{C}$ in $5 \% \mathrm{CO} 2$ in a 24 cell well plate. This condition mimics physiological conditions which includes feeding the cells by tissue culture medium (Dulbecco's Minimal Essential Medium-DMEM) and the unfavorable effect of proteolytic enzymes (trypsin). The DMEM with trypsin was replaced every day with a fresh one.

Each day 15 samples (3 groups, G2-4) were submerged in mouthwashes in the same way as previously described, twice daily every 12 hours ( 7 times in all). After treatment the F-PRF pieces were washed in PBS for 10 seconds to remove the mouthwash.

Between mouthwash baths the F-PRF pieces were kept in the incubator. The control group (G1, 5 pieces) was not treated with mouthwash but it followed the same procedure. The viability assay was performed after 3 days of incubation.

\section{Results}

The cell viability indexes can be seen in figure 1 . There was a remarkable decrease even after a short 30 second mouthwash treatment, especially G2 (CHX), as it showed a $22 \%$ decrease. In the case of Listerine (G3) and Elmex (G4) the viability drop was more moderate but still reached $15-19 \%$. There was significant difference between $\mathrm{G} 1$ and the treated groups $(\mathrm{p}<0.01)$.

After 3 days $\sim 50 \%$ viability loss was detected in the Listerine and chlorhexidine groups. The Elmex treatment showed a better result (56\% viability). The viability results presented a significant difference $(\mathrm{p}<0.001)$ between the control group (G1) and the treated groups (G24) after 30 seconds and after 72 hours as well. There was no significant difference $(\mathrm{p}<0.001)$ among the 3 treated groups $(\mathrm{G} 2-4)$.

\section{Discussion}

The viability of cellular elements of any PRF membrane is crucial for satisfactory tissue and bone regeneration. PRF is a kind of transient between a cell mixture and a solid tissue. The most numerous cells are PLs and LCs but red blood cells (RBCs) and some stem cells can also be found. In the absence of mitochondria, RBCs do not play an important role in this assay. The F-PRF "viability" is the result of mixed viability indexes of different cells. PLs are the most metabolically active "cells" without nuclei. PLs have 5-8 mitochondria, so they represent a remarkable viability index in F-PRF apart from LCs [25]. PLs and lymphocytes have the highest oxygen consumption rate in oxidative phosphorylation while monocytes have a moderate rate and the neutrophils mostly use glycolysis [26]. The MTT assay is based on the activity of oxidative phosphorylation enzymes predominantly, so it mostly represents the number of active PLs and lymphocytes, and less so the neutrophils.

One of the main advantages of the F-PRF membrane is the homogenous cell distribution [24]. This was confirmed by the viability test because the standard deviation (SD) was not too high within the different experimental groups which means that each sample contained a similar number of cells in comparison to the L-PRF membrane where the cellular distribution is zonal and inhomogeneous [27].

MTT assay is a cheap, simple, and reliable method and does not require laborious processing. It provided proper quantitative results in F-PRF viability testing. The assay is suitable for any platelet-rich product viability investigation to test the impact of any agent on cell viability, and can show the predictable potential of local tissue morphogenesis.
The viability of the cells of F-PRF decreased after a 30-second mouthwash treatment and the fall was dramatic after 3 days of treatment in spite of cell culture conditions. Chlorhexidine in particular had a negative impact on cell viability but Listerine and Elmex showed similar results without significant difference. The disintegration of the F-PRF membrane in the presence of a proteolytic enzyme was quite slow during the first week but accelerated during the $2^{\text {nd }}$ week as reported earlier [24]. The samples could not withstand the double rigor of mouthwash and enzyme treatment. After 72 hours the G1 control group lost only $9 \%$ of its viability so the difference ( $9 \% v s$ $\sim 50 \%$ ) was the result of the mouthwash treatment.

There is some stress between the conventional postoperative surgical aim (kill pathogenic bacteria) and the principle of regenerative dentistry (preserve regenerative cell viability). We have to find the balance between these two aspects so dental surgeons can have a proper approach and thinking on cell levels in PRF surgery. The chance for better cell survival means better tissue regeneration. In spite of successful reports using PRF membranes in maxilla without primary wound closure and postoperative chlorhexidine rinsing, the potential harmful effect of mouthwashes does exist $[2,6]$.

The lower part of the oral cavity potentially has a longer contact, so in mandible regeneration using PRF membrane alone or in sticky bone there is probably a higher risk. The ideal rinsing solution prevents postoperative infection but does not have an unfavorable impact on cells and a healthy microbiome.

\section{Conclusion}

Intact platelets, leukocytes, and stem cells of PRF play a crucial role in the local bone augmentation releasing cytokines and growth factors. The routinely administered postoperative mouthwashes especially CHX decreases the cell viability of PRF. A 30-second mouthwash treatment diminished the fresh F-PRF viability significantly by $15-$ $21 \%$. After 72 hours $(2 \times 30 \mathrm{sec}$ day $)$ of treatment, the viability loss was $\sim 50 \%$. The isolation of the PRF membrane from oral liquids and the application of less aggressive mouthwashes are recommended for at least 5-7 days after PRF surgery.

The in vitro F-PRF viability test results do not show the same results presumably as in clinical conditions. The tissue culture conditions combined with trypsin mimic the effect of oral saliva- but further investigations are necessary to identify the ideal conditions.

\section{Declarations}

\section{Statement on ethics approval and consent}

Blood samples were collected with informed consent. Experiments were in accordance with the ethical standards of the Regional Research and Ethic Committee of Györ. Approval date: $18^{\text {th }}$ January 2021. ID number: $2 / 2021$

\section{Consent for publication}

Not applicable

\section{Availability of data and materials}

The datasets used and/or analysed during the current study are available from the corresponding author on reasonable request.

\section{Competing interests}

The authors declare that they have no competing interests.

\section{Funding}

Not applicable 


\section{Author's contributions}

LC designed the experiment and adopted the viability assay and interpreted the data.

ÁB was involved in the phlebotomy and PRF membrane preparation.

ZTB and RG were involved in study design, search of relevant references, and set the clinical consequences of the study.

DC performed the viability assay.

JK was a major contributor in writing the manuscript and in searching the optimal laboratory technical requirements.

All authors read and approved the final manuscript.

\section{Acknowledgements}

We would like to express our thanks to John Kowalchuk for his support in editing the manuscript.

\section{References}

1. Assad M, Bitar W, Alhajj N (2017) Closure of oroantral communication using platelet-rich fibrin: a report of two cases. Ann Maxillofac Surg 7: 117-119.

2. Demetoglu U, Ocak H, Bilge (2018) Closure of Oroantral communication with plasma-rich fibrin membrane. J Craniofac Surg 29: e367-e370.

3. Sohn D, Huang B, Kim J, Park WE, Park CC (2015) Utilization of autologous concentrated growth factors (CGF) enriched bone graft matrix (sticky bone) and CGF-enriched fibrin membrane in implant dentistry. J Implant Adv Clin Dent 10: 11-29.

4. Al-Hamed FS, Tawfik MAM, Abdelfadil E (2017) Clinical effects of platelet-rich fibrin (PRF) following surgical extraction of lower third molar. Saudi J Dent Res 8: 19-25.

5. Gülşen U, Şentürk MF (2017) Effect of platelet rich fibrin on edema and pain following third molar surgery: a split mouth control study. BMC Oral Health 17: 79.

6. Mozzati M, Gallesio G, Margherita M, Del Fabbro M (2020) Concentrated Growth Factors vs. Leukocyte-and-Platelet-Rich Fibrin for Enhancing Postextraction Socket Healing. A Longitudinal Comparative Study. Appl Sci 10: 8256.

7. Bescos R, Ashworth A, Cutler C, Brookes ZL, Belfield L, et al. (2020) Effects of Chlorhexidine mouthwash on the oral microbiome. Sci Rep 10: 5254.

8. Woloski J (2018). https://www.geisinger.org/health-and-wellness/ wellness-articles/2018/01/29/20/46/is-mouthwash-safe-to-useevery-day.

9. Fujioka-Kobayashi M, Schaller B, Pikos MA, Sculean A, Miron RJ (2020) Cytotoxicity and Gene Expression Changes of a Novel Homeopathic Antiseptic Oral Rinse in Comparison to Chlorhexidine in Gingival Fibroblasts. Materials 13: 3190.

10. Lourenço ES, Mourão CFAB, Leite PEC, Granjeiro JM, Calasans-Maia $M D$, et al. (2018) The in vitro release of cytokines and growth factors from fibrin membranes produced through horizontal centrifugation. J Biomed Mater Res A 106: 1373-1380.
11. Mosmann T (1983) Rapid colorimetric assay for cellular growth and cytotoxic assays. J Immunol Methods 65: 55-63.

12. Green LM, Readed JL, Ware CF (1984) Rapid colorimetric assay for cell viability: application to the quantitation of cytotoxic and growth inhibitory lymphokines. J Immunol Methods 70: 257-268.

13. Klebe RJ, Harris JV (1984) A technically simple "non-lethal" vital staining procedure for viral plaque and cell transformation assays. Brief report. Arch Virol 81: 359-362.

14. Levitz SM, Diamond RD (1985) A rapid colorimetric assay of fungal viability with the tetrazolium salt MTT. J Infect Dis 152: 938-945.

15. Pagé $M$, Bejaoui $N$,Cinq-Mars B, Lemieux $P$ (1988) Optimatization of the tetrazolium-based colorimetric assay for the measurement of cell number and cytotoxicity. Int J Immunopharmac 10: 785-793.

16. Comley JC, Townson S, Rees MJ, Dobinson A (1989) The further application of MTT-formazan colorimetry to studies on filarial worm viability. Trop Med Parasitol 40: 311-316.

17. Curtil A, Larese A, Champsaur G, Bétuel H (1991) Methyltetrazolium test for cryopreserved cardiac valve viability (abstract). Cryobiology 28: 565-566.

18. Ferrera R, Larese A, Berthod F, Guidollet J, Rodriguez C, et.al. (1993) Quantitative reduction of MTT by hearts biopsies in vitro is an index of viability. J Mol Cell Cardiol 25: 1091-1099.

19. Stockert JC, Horobin RW, Colombo LL, Blázquez-Castro A (2018) Tetrazolium salts and formazan products in Cell Biology: Viability assessment, fluorescence imaging, and labeling perspectives. Acta Histochemica 25: 159-167.

20. Csönge L, Bravo D, Newman-Gage H, Rigley T, Conrad EU, et al. (2002) Banking of Osteochondral Allografts. Part I. Viability Assays Adapted for Osteochondral and Cartilage Studies. Cell Tissue Bank 3: 151-159.

21. Evans WED (1963) The chemistry of death. $1^{\text {st }}$ edition, Springfield, IL, 28.

22. Malinin TI, Perry VP (1967) A review of tissue and organ viability assay. Cryobiology 4: 104-115.

23. Smith DE, Robins E, Eydt KM (1957) The validation of the quantitative histochemical method for use on post-mortem material: I. The effect of time and temperature. Laboratory Investigation 6: 447-457.

24. Csönge L, Bozsik Á, Tóth-Bagi Z, Gyuris R, Kónya J (2021) Regenerative medicine: characterization of human bone matrix gelatin (BMG) and folded platelet-rich fibrin (F-PRF) membranes alone and in combination (sticky bone). Cell and Tissue Banking 22: 711-717.

25. Melchinger H, Jain K, Tyagi T, Hwa J (2019) Role of Platelet Mitochondria: Life in a Nucleus-Free Zone. Front Cardiovasc Med 6: 153.

26. Kramer PA, Ravi S, Chacko B, Johnson MS, Darley-Usmar VM (2014) A review of the mitochondrial and glycolytic metabolism in human platelets and leukocytes:Implications for their use as bioenergetic biomarkers. Redox Biol 2: 206-210.

27. Crisci A, Manfredi S, Crisci M (2019) The L-PRF membrane (fibrin rich in platelets and leukocytes) and its derivatives useful as a source of stem cells in wound surgery. J Stem Cell Rep 1: 1-11. 